ISSN: $1130-3743$

DOI: http://dx.doi.org/10.14201/teoredu2014261119135

\title{
ARTEFACTOS CULTURALES Y ALFABETIZACIÓN EN LA ERA DIGITAL: DISCUSIONES CONCEPTUALES Y PRAXIS EDUCATIVA
}

\author{
Cultural artifacts and literacy in the digital era: \\ conceptual discussions and educational praxis
}

\section{Artefacts culturels et la littératie à l'ère digitale: discussions conceptuelles et pratiques éducatives}

Eloy MarTOS y Alberto E. MARTOS García

Universidad de Extremadura. Facultad de Educación. Departamento de Didáctica de las Ciencias Sociales, las Lenguas y las Literaturas. Avd. de Elvas, s/n. 06071 Badajoz.Correo-e: emarnun@gmail.com; aemargar@gmail.com

Fecha de recepción: enero de 2014

Fecha de aceptación definitiva: abril de 2014

Biblid [(1130-3743) 26, 1-2014, 119-135]

\section{RESUMEN}

Modernamente, han surgido diversas elaboraciones teóricas en torno al concepto de "artefacto", desde diversas áreas y paradigmas de las ciencias sociales y las humanidades. Sin pretender agotar la revisión teórica multidisciplinar, el artículo describe algunos ejes de las discusiones conceptuales y criterios para posibles intervenciones didácticas dentro de las prácticas educativas. El concepto de "cultura letrada" ha sido puesto en valor por Roger Chartier y otros autores. La noción de artefacto cultural" ha sido objeto de debate por autores como Holland y Cole. En este artículo se proponen varias aplicaciones de los citados conceptos a la realidad educativa, 
teniendo en cuenta los cambios sociales y tecnológicos, con particular énfasis en el enfoque artifactual de la literacidad de Pahl y Rowsell.

Palabras clave: artefacto cultural, alfabetización, nuevos estudios de literacidad, cultura letrada, cibercultura.

\section{SUMMARY}

In modern times, various theoretical elaborations around the concept of "artifact", arose from different areas and paradigms in the social sciences and humanities. Without attempting to exhaust the multidisciplinary theoretical review, the article describes some axes of conceptual arguments and criteria for possible didactic interventions in educational practices. The concept of "literate culture" has been put in value by Roger Chartier and other authors. The notion of "cultural artifact" has been discussed by authors such as Holland and Cole. This article suggests several applications of these concepts to the educational reality, taking into account the social and technological changes, with particular emphasis on the artifactual approach of literacy by Pahl and Rowsell.

Key words: cultural artifact, literacy, new literacy studies, literate culture, cyberculture.

\section{SOMMAIRE}

Dans les temps modernes, des élaborations théoriques diverses autour du concept de "artefact", sont nées de différents domaines et de paradigmes dans les sciences sociales et humaines. Sans chercher à épuiser l'examen théorique multidisciplinaire, l'article décrit certains axes des arguments conceptuels et des critères pour les possibilités d'interventions didactiques dans les pratiques éducatives. La notion de "culture écrite" a été mise en valeur par Roger Chartier et d'autres auteurs. La notion de "artifact culturel" a été examinée par des auteurs tels que Holland et Cole. Cet article suggère plusieurs applications de ces concepts à la réalité éducative, en prenant en compte les changements sociaux et technologiques, l'accent étant mis sur l'alphabétisation des approche artéfactuelle Pahl et Rowsell.

Mots clés: artefact culturel, alphabétisation, nouvelles études de l'alphabétisation, culture écrite, cyberculture.

\section{LA TEORÍA DE lOS ARTEFACTOS EN SU ÁMBITO CULTURAL, ESTÉTICO Y EDUCATIVO}

Cuando hablamos de arfefactos hablamos de todo objeto fruto del ingenio bumano, en cualquier área de actuación y con cualquier fisonomía; puede ser grande 
o pequeño, eso da igual: así, una roca es un objeto natural, pero un ídolo esculpido sería un artefacto. Los objetos asociados a la alfabetización dependen de la cultura material predominante: hablamos, pues, de papel, tinta, bolígrafo, libro..., como hoy se habla de otros dispositivos digitales, por ejemplo, tinta electrónica, ebook, etc. Por otro lado, las nuevas prácticas culturales, con sus instalaciones y performances, han planteado formas y soportes de lectura y escritura experimentales que desbordan las preconcepciones y los hábitos comunes en esta materia, dando lugar a las llamadas nuevas textualidades, que por ejemplo buscan la lectura sinestésica o multisensorial, la posibilidad de leer un texto de forma multisensorial. De modo que los objetos o artefactos estéticos de la poesía visual cada vez más se liberan de la forma logocéntrica para irradiar sus propuestas comunicativas hacia otros discursos y entornos, hacia la denominada transliteratura.

En otro ángulo de visión, desde un punto de vista "expandido", y especialmente en contextos de psicología de la educación, hablamos también de artefactos cuando nos referimos a "ingenios mentales", que cada vez más siguen la regla general de la evolución de la tecnología hacia la desmaterialización y la miniaturización, es decir, cada vez son más pequeños y su interfaz material más ligera y fácil de manejar, como ocurre con las tabletas. De hecho, se ha acuñado el concepto de mentefacto (Huxley, 1955; De Zubiría, 1997) en el campo de la pedagogía conceptual y también para describir las representaciones visuales de conceptos tales como los organizadores gráficos. Pero tanto los mentefactos como los llamados sociofactos en realidad lo que quieren decir es la presencia de "construcciones" que no son tangibles o materiales, ya sean relaciones de parentesco, representaciones de creencias o una estructura proposicional, frente al concepto clásico de artefacto como objeto con soporte físico o material.

Dada, pues, esta amplitud de matices, procede hacer una deconstrucción del concepto a fin de conciliar, si es posible, algunas de estas aproximaciones y ofrecer un apoyo a propuestas de intervención estética, cultural o educativa, en tanto que una de las dimensiones propias de las ciencias sociales es no sólo describir sino transformar los entornos conforme, en este caso, a paradigmas de emprendimiento social, que es donde esta temática está cobrando actualidad.

\section{LOS ARTEFACTOS CULTURALES Y LA ALFABETIZACIÓN}

Dentro de los Nuevos Estudios de Literacidad (Cassany, 2006) los eventos letrados se descomponen en elementos como los escenarios, los participantes, las rutinas y los artefactos. Este nuevo concepto involucra todos los objetos que son elaborados de forma artificial, esto es, que conllevan tanto una manufactura como un diseño intelectual, por así decir. En la cultura escrita el artefacto por excelencia es el libro, en sus diferentes formatos -desde el códice a la tableta-, que han ido jalonando la historia de la lectura. Pero la historia de las tecnologías del papel y del mundo audiovisial y digital han demostrado cómo tecnologías que en su origen no 
se inventaron como vehículo de lectura y escritura han devenido sin embargo en grandes artefactos alfabetizadores: el móvil, por ejemplo.

Debemos a Holland y Cole (1995) la elaboración de una teoría del "artefacto cultural" que supone una síntesis entre los conceptos de la escuela rusa (Vygotsky, 1994) y otras aportaciones de las ciencias sociales. Los artefactos culturales son sin duda piezas básicas del engranaje del ser humano con el mundo físico y de las personas entre sí. Un rasgo esencial es su apertura o bifrontalidad: son al mismo tiempo materiales e ideales (es decir, conceptuales o simbólicos), es decir, tienen una base tangible pero a la vez son intangibles, porque funcionan creando y adquiriendo significaciones. Un palo, una pluma, un lápiz, un punzón... son herramientas que comparten la posibilidad de "escribir" al aplicarse sobre distintos soportes (arena, papel, piedra...), pero que cuyo significado sociocultural excede su propia base tecnológica. Así, que un libro se categorice, para la comunidad, como una guía de teléfonos, un periódico desechable o como una escritura sagrada revela el plus de significación que se le confiere a cada objeto en función de tales atribuciones culturales.

En efecto, Holland y Cole (1995) vinculan el concepto de cultura y el de artefacto cultural de forma muy estrecha. La cultura es a las personas lo que la biosfera es a los animales, una especie de semiosfera (Lotman, 1979) en que crecen a partir de las construcciones modulares de la mente y de los contextos culturales de la acción. Y donde los artefactos son el mundo material e ideal que les rodea, con los sentidos atribuidos por una tradición y un contexto.

En consecuencia, ambos conceptos se interpenetran. La cultura sería, pues, un depósito vivo de "los artefactos de las generaciones precedentes", somos lo que somos a partir de las "construcciones" - en el más amplio sentido de la palabra- de nuestros antepasados. Nuestra forma de vivir, calles, escuelas, campos, pero también nuestros imaginarios sociales (leyes, creencias, pensamiento, arte y literatura [Castoriadis, 1999]), son el fruto de todo ese quehacer de siglos, plasmados en artefactos culturales aún visibles entre nosotros, algunos de ellos transmutados, por ejemplo, un "grifo", pero que conserva en su propio nombre el vestigio de una cosmovisión anterior donde el objeto y la creencia -el animal mitológico- eran una misma cosa.

Por otro lado, la definición de artefacto cultural nos revela su pluridimensionalidad, al subrayarse que se trata de un aspecto del mundo material con un uso recordado colectivamente. En otras palabras, lo que conocemos como un soporte dado, por ejemplo un libro o el grifo del ejemplo citado, es un objeto material (esfera de la cultura material) que es usado o apropiado por alguien (esfera de la individualización, del ingenio o emprendimiento), y que se conserva en relación a unos valores que forman parte de una herencia cultural o memoria colectiva (esfera de la memoria o del patrimonio) y que son asumidos, enseñados o reconocidos como tales por parte de la comunidad (esfera de la instrucción o la socialización). Por todo eso, el objeto "libro" o "grifo" es parte fundamental de nuestra cultura, es decir, de la cultura escrita, a diferencia de una sociedad ágrafa, de nuestra cultura 
del agua, que ha creado conducciones de agua con un dispositivo de salida o regulación, pero no formaría parte de un "depósito de artefactos" con otros esquemas, en ambos casos.

Siguiendo a Olson (1994), recuérdese que el principal rasgo del pensamiento letrado es que trata de representaciones como afirmaciones, ecuaciones, mapas y diagramas y no del mundo en sí mismo, en coherencia con lo que las neurociencias describen sobre el funcionamiento cerebral, que, por otra parte, no puede entenderse sin los distintos contextos culturales que lo moldean. Desde esta óptica, la propia mente (entendida como autoconciencia) es un gran artefacto cultural formado y modelado en contacto con los productos de las actividades letradas presentes y pasadas, capaces de crear todo tipo de construcciones. Igual que, en el campo concreto de la alfabetización, las prácticas letradas son las que crean identidades lectoras concretas (v.gr. lectores expertos, ocasionales, no lectores), en el campo social en el sentido más amplio, es la impregnación con la cultura como artefacto social la que crea una identidad, en juego o en interacción con todas sus "construcciones". Como con un mecano o con el juego de piezas "Lego", las posibilidades son infinitas, pero los resultados siempre dependen del momento, los agentes, los escenarios, el tipo de actividades, etc., es decir, todos los componentes que definen los event literacy o eventos letrados, las prácticas de lectura y escritura.

El artefacto, así considerado, no sólo tiene utilidades inmediatas o "cercanas", sino que confiere identidad, pertenencia y, en distinta medida, autoconciencia. En efecto, la integración en la cultura letrada nos provee de una identidad, nos hace pertenecer a una comunidad y sus códigos y artefactos. Por ejemplo, en el caso de los llamados "niños salvajes", se observa bien cómo la naturaleza del ser humano sólo se realiza o completa en el seno de cultura que lo recibe. La comprensión y aprehensión (en el sentido etimológico) del mundo depende del sistema simbólico del grupo que lo acoge, y sin ese vínculo social la construcción del sentido es imposible.

En un sentido más global y abierto, debemos concebir la cultura escrita como un conjunto tanto de procesos como de productos y competencias, es decir, el

ensemble des activités humaines qui impliquent l'usage de l'écriture, en réception et en production. Elle met un ensemble de compétences de base, linguistiques et graphiques, au service de pratiques, qu'elles soient techniques, cognitives, sociales ou culturelles. Son contexte fonctionnel peut varier d'un pays à l'autre, d'une culture à l'autre, et aussi dans le temps (Barré de Miniac, 2004: 31).

Con todo ello enlazamos con las tesis del antropólogo J. Goody (1996): él lo ha llamado littératie restreinte o elargie, cultura escrita de uso restringido o bien expandido, extendido. Según Goody, es la irrupción de la cultura escrita lo que acelera los cambios sociales, originados en las culturas antiguas con los excedentes agrícolas o la cultura de las ciudades, para determinar una especie de "tecnología del intelecto". Es decir, si bien al principio la escritura sirvió para gestionar estos 
excedentes, con el tiempo permitió el paso, seguimos las ideas de Havelock (1996) acerca de la oralidad y su sistema de transmisión y repetición de la información, hacia un modo nuevo donde los mensajes se podían re-escribir y repensar por un mismo sujeto, dando origen así a la "conciencia del yo", a la emergencia de la subjetividad.

La asociación entre cultura escrita y tecnología del intelecto se explica no sólo por el surgimiento de unos nuevos útiles de escritura o soportes de la misma sino también por la formación requerida en nuevas competencias, un uso nuevo de la vista, y la producción de artefactos culturales nuevos, como los libros y los pergaminos, que son guardados, consultados o compuestos conforme a unos determinados saberes: Goody pone en cuestión las preconcepciones que establecen la bipolarización tradicional entre oralidad y (usos de la) escritura.

La "literacía restringida" encaja bien con los usos deficitarios, como lo que se conoce incluso como "analfabetismo funcional". La "literacía extendida o expandida", en cambio, es otra manera de llamar a la "cultura letrada". Goody rechaza la bipartición entre estos dos dominios, oralidad y escritura, al contrario, muestra cómo ambos mundos se "contaminan" e interpenetran, así, afirma que "la performance orale dans les sociétés de l'écrit est influencée par la présence de l'écrit" (ibid em). En todo caso, saber, escribir y poder son ámbitos interconectados. La relación entre tecnología del intelecto y artefactos ilustra las distintas etapas de la historia de la alfabetización. En la etapa de la cultura manuscrita, el scriptorium medieval constituía un universo de objetos bien conocidos.

La etapa de la cultura tipográfica supone otra tecnología, otras prácticas, otros artefactos: la imprenta, el editor, las pruebas, etc., configuran otro mundo diferente al del amanuense. Si, como se ha dicho, Internet, en la etapa de la cultura postipográfica, supone un vuelco semejante al de la Imprenta no es sólo porque se haya convertido en la imprenta del siglo XXI, sino porque han variado las formas (el texto electrónico, el hipertexto) y las relaciones (el lector no es ya un receptor pasivo sino un "prosumidor" y ello se ha intensificado con las herramientas de la web 2.0).

\section{LOS ARTEFACTOS EN EL ÁMBITO DE LAS PRÁCTICAS Y LOS MATERIALES EDUCATIVOS DE LECTURA Y ESCRITURA}

Es un lugar común hablar de los orígenes de la escuela como bija de la cultura letrada y de la imprenta, igual que no es menos verdad que los niños y jóvenes actuales son bijos de una cultura digital y mediática que los convierte en lo que se ha llamado "nativos digitales" (Prensky, 2005). Sin embargo, como veremos, cultura letrada y cibercultura no son polos antagónicos. Sí es cierto que estando a caballo, pues, entre los textos impresos y los textos electrónicos, la confusión se extiende sobre muchos jóvenes, porque sólo saben hacer un uso epidérmico de ambos mundos y porque hay también un relativo desconcierto entre los propios profesionales de la educación sobre las mejores vías para conciliar ambos mundos. 
De una cultura donde se apilaban los libros en estantes o mesas, a las que accedía el usuario, y donde la información estaba depositada en estos soportes, hemos pasado a los nuevos escenarios. En efecto, la fractura cultural se hace más evidente cuando contrastamos los escenarios clásicos y los más emergentes, tanto en terreno educativo como cultural: de las bibliotecas o salas de estudio con enciclopedias y libros apilados, hemos pasado a aulas con la hegemonía ahora de los dispositivos informáticos y con incluso una disposición espacial diferente. La suplantación parece brusca, pero lo cierto es que entre los nuevos artefactos y los nuevos escenarios el eje parece desplazarse hacia lo tecnológico. La percepción del estudiante es que los viejos escenarios y artefactos (el libro, la mesa de escribir a mano, el espacio para contar cuentos...) están obsoletos, y que la "ciencia" les va a venir por una vía "digital", como si hubiera una "máquina maravillosa" que obviara los propios procesos cognitivos, hasta tal punto la fetichización de la tecnología es una constante entre los más jóvenes.

El problema, pues, puede radicar en la excesiva dependencia, y el olvidar que la mente letrada se caracteriza por desarrollar el pensamiento crítico y creativo, lo cual implica un proceso de autoconciencia (Olson, 1994), es decir, dirigirse hacia el interior, hacer preguntas, hipotetizar, repensar (releer) las cuestiones, algo característico de la cultura escrita, y que no puede ser suplantado ni por el ordenador ni por Internet, porque éstos no pueden pensar por nosotros. La diferencia está en entender que estos medios, por potentes que sean -y lo son- son en gran medida "prótesis" y no "sustitutos" de la acción básica educativa, que no se limita a enseñar, por parte del profesor, o a aprender/construir, por parte del alumno, sino a interaccionar, compartir, colaborar y dar respuestas activas a los problemas e interrogantes. Esto se contradice con ciertos usos de estas "generaciones interactivas" (Bringué y Sádaba, 2008), puramente individualistas, incluso cuando son más transgresoras.

Parece evidente que hay que desarrollar habilidades que no dependan sólo del uso de tecnologías, sino que usen éstas como herramientas, en combinación con otras, como los propios libros o los otros medios, por ejemplo, se habla de que hay que saber combinar las actividades que tienen como foco las redes sociales, pero también las que implican el "conocimiento cara a cara". Reivindicar la cultura escrita en su totalidad, no sólo una parte (los libros de un lado o la cultura digital del otro), es también enseñar a amar la cultura escrita abarcándola en la totalidad de sus manifestaciones, pues, como nos recuerdan Barton y Hamilton (1998) bay prácticas de lectura y escritura que son más visibles y prestigiadas que otras, pero esto no se debe a su naturaleza intrínseca o a supuestos criterios de calidad, sino a otros factores más ligados al estatus o a la valoración social. Por ejemplo, los llamados "egodocumentos" (Castillo, 20105) por los historiadores (i. e. textos centrados en el "yo", diarios, agendas, memorias, biografías, historias de vida...) rara vez traspasan del ámbito de lo privado o lo familiar, a pesar de que sabemos que "toda vida merece ser contada" y que son textos modélicos en tanto que narrativas identitarias y memoria de estratos sociales más "invisibilizados", por ejemplo, sectores desfavorecidos de diferentes adscripciones. 
Por su parte, el cuento popular ha tenido siempre gran éxito porque, como dice Benjamin (1973, 303), es la "experiencia que corre de boca en boca", es decir, tiene una dimensión colectiva que sin embargo cada uno es capaz de apropiarse, de personalizar e interiorizar para sus propias necesidades y aspiraciones. Ahora bien, para tener la posibilidad social de tener una palabra propia es clave el construir una escucha, de ganarse una escucha ${ }^{1}$. La cultura letrada multiplica estas posibilidades porque en realidad cada texto, cada género, cada autor es una posibilidad de autoafirmación a través de la apropiación que cada uno hace de los mismos, frente al mensaje plano y estereotipados de los medios de comunicación. Como argumenta Italo Calvino (1992), los clásicos lo son porque sus propuestas siguen llenándonos de interrogantes, de enigmas pendientes de resolver, para lo cual releemos sus mensajes desde nuestras propias mentalidades y contextos de hoy, es decir, los actualizamos y comentamos continuamente.

Por tanto, la cultura letrada no debe reducirse a un pasado libresco, ni a lo erudito, ni a un bagaje de citas, ni tampoco se personifica en un bibliófilo o en un sabio aislado del mundo, sino es todo ese universo de conocimiento compartido (no sólo la literatura sino el pensamiento, las ciencias, la historia, el derecho...), susceptible de moldear la "mente letrada" (Olson), la que explora e indaga, la que conforma a la postre una (auto)conciencia. Por otro lado, "leer hoy es un montón de prácticas diferentes. Primero, prácticas históricas que no han desaparecido y que se superponen a las más modernas» ${ }^{2}$. No se puede pues hablar de lectura o alfabetización en singular sino en plural. La cultura académica y escolar ha primado, en el contexto europeo, ciertas prácticas, por ejemplo, de entrada, un libro era más encomiable que un tebeo. Por otro lado, la lectura se encuentra fragmentada, es decir,

cada institución no tiene que ver con las otras; la escuela no tiene nada que ver con la biblioteca, la biblioteca no tiene nada que ver con la escuela, los intelectuales no tienen nada que ver con la lectura de la gente, la gente no tiene nada que ver con los intelectuales; la relación de los diversos sectores que tienen que ver con la lectura es nula. Segundo: Ni la oralidad, ni la cultura oral, ni la cultura de la imagen aparecen como claves del mundo de lectura. Tercero: todo lo que se habla de leer como parte de un ejercicio de participación ciudadana queda completamente anulado y no se ve ni en la escuela ni en las bibliotecas; la noción de lectura es una noción instrumental que está muy ligada a la función o bien escolar, o bien después, la función laboral ${ }^{3}$.

1. Martín Barbero, J. (2005) Nuevos modos de leer. Texto realizado para el seminario Mito o realidad del libro. V Feria Internacional del Libro. Bogotá, disponible en ww.c3fes.net/docs/ modosleerbarbero.pdf.

2. MARTÍN BARBERO, ibidem.

3. Ibidem. 
Las consecuencias de tal situación son claras: si la lectura es plural, poliédrica y fragmentada, la percepción de los alumnos no es menos atomizada e interrumpida. Se echa en falta un bilo conductor que ponga en valor todas estas distintas prácticas y "fragmentos de realidad", y este hilo conductor sólo puede ser uno: el mediador, el maestro. Ahora bien, la cibercultura no es precisamente propicia a estos planteamientos. Si se nos permite la comparación con lo que ya ocurriera con los postulados protestantes sobre la lectura de los textos sagrados, si no se admite, por regla general, la figura de un intermediario y se tiende a un "libre examen de los textos", entonces entenderemos la profusa selva de la cibercultura. Se comparten las experiencias (por ejemplo, los moderadores, los "beta-readers" de muchas páginas de la denominada fan fiction), pero no se admite un canon de interpretación ni se establece una jerarquía interpretativa. De hecho, un cibernauta "novel" puede incursionar en la Red en páginas de sectas o similares que den versiones disparatadas, y, para ese internauta, serán testimonios colocados casi al mismo nivel que otras páginas más fiables.

Admitir la diversidad de continentes (por ejemplo, la cultura del "papel", el libro, las tapas, la textura de papel, etc., lo mismo que los nuevos dispositivos creados al amparo de la cultura digital) no soluciona este problema de la posible manipulación de los contenidos. Con todo, parece lógico que derivemos hacia una cultura híbrida, que "albergue" lo mismo a las nuevas y a las viejas tecnologías. La realidad impone la necesidad de vivir en esos dos mundos, de adoptar una mentalidad "anfibia" que le permita, eclécticamente, tomar lo mejor de los dos ámbitos, puesto que estamos ante una cultura ya irremediablemente híbrida. Las formulaciones excluyentes o restrictivas de cultura letrada no resisten un análisis exigente, como tampoco lo resiste la banalización de la cibercultura; al contrario, es preciso trazar los puentes o vías de conexión entre ambas realidades y sacar las conclusiones pertinentes. Detrás de las propias modas audiovisuales, de fenómenos aparentemente llamativos (por ejemplo la reciente compra de Marvel por parte de Disney) se esconden no sólo aspectos empresariales o económicos, sino la propia raíz de la cibercultura como cultura emergente que necesita otra mirada, y que se va a beneficiar de la cultura letrada, igual que ésta, en su día, se apropió de la cultura oral.

El problema sigue siendo el que plantea Chartier (1994): cómo pasar de una lectura salvaje de objetos no canónicos o no reconocidos/prestigiados como lectura por parte de la tradición letrada. Daniel Link (1997), por su parte, vislumbra soluciones, desde el momento en que Internet y la cultura letrada son más aliadas que ésta y la cultura industrial o audiovisual de los medios masivos, que sólo parecen ofrecer "entretenimiento anestésico". Por ejemplo la cultura digital está exigiendo un grado mayor de implicación y participación, es decir, no sólo ve a los receptores como "consumidores" sino como "prosumidores" (Quain 2002), es decir, como productores y consumidores a la vez. 


\section{ARTEFACTOS EDUCATIVOS PARA EL SIGLO XXI}

Sabemos que en realidad el mundo de la comunicación verbal se compone de "flujos textuales" que crean una dinámica desde la producción a la recepción de los textos, y a la que no es ajeno precisamente el problema de los continentes o formatos, pues el "recipiente" por así decir no es sólo un contenedor de textos sino que condiciona fuertemente el texto, como ha puesto de evidencia la historia de la lectura. Por eso Chartier ha hablado acertadamente de la textualidad del libro y de la materialidad del texto, de tal forma que el artefacto de lectura/escritura aborma el texto, igual que éste se ve condicionado por el formato material final. Por ejemplo, la narración serial, que empieza con las novelas por entregas, se ve alentada ahora por toda la revolución digital, donde podemos grabar una serie de ficción y verla "a demanda", cosa que no era posible con el cuentacuentos clásico.

Puesto que los artefactos son simultáneamente ideales (conceptuales) y materiales, se ha hablado de Internet no sólo como una tecnología sino como un artefacto cultural. Y si las prótesis o los gadgets, como las gafas o los marcapasos, son artefactos o extensiones de nuestro cuerpo, sin duda Internet y todos los dispositivos de la nueva era digital (móviles, PDA, Ipad, etc.) son la "prótesis" más extensa, pues nos permiten ampliar nuestra percepción y nuestro pensamiento a ámbitos cada vez más amplios de la realidad.

La forma y funcionalidad de estos artefactos está cambiando continuamente, así un móvil ha pasado de ser un teléfono a muchas otras funciones. De modo análogo, ciertas "construcciones" mentales, como por ejemplo un gráfico, croquis o esquema que alguien podía llevar en forma de mapa, cuaderno, etc., se desarrolla ahora en multitud de soportes y modalidades. Así, Google Maps, por citar un caso, crea multitud de formas cartográficas que van desde la foto al mapa rotulado, e incluso la llamada cartografía conceptual nos permite un pensamiento no ya individual y lineal sino global y colaborativo a través de software como mindmand y otros.

Ahora bien, distintos grupos sociales poseen interpretaciones radicalmente distintas de un artefacto. Así, se ha hablado de youtube, por ejemplo, como un artefacto sociotécnico que ha recorrido diversas etapas. Primero, fue una invención que se perfeccionó para pasar de ser un sitio de intercambio de vídeos a una red social:

Un artefacto puede ser producido y desarrollado por ingenieros, científicos o aficionados talentosos. Pero cuando sale a la luz es resignificado por diferentes grupos e individuos, cuyos intereses pueden y suelen ser diferentes a los inicialmente pensados por los inventores, y hasta entrar en conflicto unos con otros. La popularidad de YouTube muestra que ciertos problemas tecnocientíficos sin duda fueron resueltos. Pero también da cuenta de una sociedad que ya venía hacía tiempo demandando más superficies que líneas y practicando diversas formas del muy americano "do it yourself". YouTube aglutina sistémicamente un conjunto de actores de origen humano (proveedores, anunciantes, inversores, corpus jurídicos, entre otros), los movimientos a favor del software libre, las licencias Creative 
Commons y otras formas de expresar que compartir ni es delito ni es inapropiado, también son parte importante del contexto donde este tipo de sitio puede tener su mayor éxito y también su mayor resistencia ${ }^{4}$.

Ciertamente, si distintos grupos sociales poseen interpretaciones radicalmente distintas de un artefacto, también sucede que son los grupos más relevantes de una sociedad, en un área determinada, los que dan significado al artefacto. Es lo que ha ocurrido en el campo educativo: la educación y la universidad, herederas al fin y al cabo de una enseñanza oral y logocéntrica, de la lectio escolástica, han ido creando sucesivos artefactos expositivos y reproductivos de los discursos canónicos, el libro y el cuaderno, por ejemplo.

Las prácticas y los materiales educativos actuales revelan un mundo diverso y heterogéneo, donde además no caben patrones ni generalizaciones sobre la eficiencia de tal o cual método/material; por el contrario, los entornos educativos deben estudiarse de forma "situada", contextualizada, y es sólo en ese marco donde cabe estudiar las distintas modalidades de prácticas y artefactos.

Las representaciones de las prácticas de lectura en subcomponentes básicos, como los escenarios, los agentes, las actividades y los artefactos mismos, permite resituar éstos no sólo como simples aditamentos sino como elementos mediadores que otorgan sentido a una actividad: un folleto, por ejemplo, es muy distinto si se refiere a un máster universitario que a una promoción de rebajas. Para el primer caso un grupo lo interpreta como un plan de estudios o un contrato de obligaciones, enmarcable en el contexto más amplio de la universidad; para el segundo caso, el folleto puede ser percibid o como una hoja volandera que anuncia una ganga y que sólo tiene un valor "hic et nunc".

Los imaginarios sociales (Castoriadis, 1999: 61) también han creado imaginarios educativos, donde el estudiante, según sea la filosofía de partida, es un receptor mimético (tomador de apuntes), o un constructor de tipo cognitivista (uso de mapas conceptuales), o alguien que comparte y crea colaborativamente su aprendizaje mediante lo que se ha llamado el conectivismo o conexionismo (uso de la web 2.0). Las prácticas y los artefactos educativos no pueden ser entendidos fuera de estas distintas mentalidades y contextos, pues si lo que a un profesor le interesa es enseñar a pensar, a aprender o a crear, las prácticas letradas serán radicalmente distintas a las de una enseñanza expositiva tradicional.

En la medida en que todos interpretamos y co-construimos los significados, las situaciones de enseñanza-aprendizaje deben ser analizadas como actividad conjunta, como diálogo en el sentido en el que lo define Bajtin (1974). Esto, en el campo de la educación literaria y artística, es particularmente evidente, pues no se

4. SIRI, L. "Un análisis de You Tube como artefacto sociotécnico". Revista académica de la federación latinoamericana de facultades de comunicación social, p. 9. Consultado el 12 de marzo de 2009. http://www.dialogosfelafacs.net/77/ artículos/pdf/77LauraSiri.pdf. 
trata sólo de otorgarle su parte de responsabilidad en el aprendizaje al alumno sino de ensanchar el campo de acción al entender que los referentes del aprendizaje literario no son sólo la relación autor-texto sino el otro eje, texto-público.

Este ensanchamiento de los referentes de la educación literaria implica introducir de lleno la escritura como un espacio de creatividad social, que además supone para algunos, en la línea de Paulo Freire, una forma activa de compromiso, tal como explica Martín Barbero (2005):

Hay que pasar a las lecturas. Para hacerlo hay que pasar por un nivel mediación que es la escritura. La inmensa mayoría de los documentos establecen como fundamental a la lectura, no la escritura. Hay como una especie de "frase de calle" que dice que saber leer y escribir van juntas. Pero todas las políticas son políticas de lectura; una biblioteca, por ejemplo, no tiene políticas de escritura, ni la escuela tampoco. Las políticas son de lectura y de lectura primaria, de lectura pasiva, de lectura instrumental. Hoy día para ser ciudadano, necesitamos no sólo saber leer, necesitamos saber escribir. Hemos entrado a la sociedad en la que la metáfora del escribir se ha hecho real en la virtualidad digital. Tú no puedes usar el computador sin escribir. Si tú no sabes escribir, tú no puedes disfrutar del computador, ni del internet. Se requiere de una lectura que capacite para asumir la palabra, para expresarse, para escribir. ¿Qué significa? Apropiarse de la lectura es hacer de la palabra un modo de presencia social, un modo de intercambio activo y de interacción social.

Hoy día, la lectura puede ser enormemente evasiva, implosiva; vea como está el mundo, como está la sociedad, mejor me refugio en la lectura; la lectura puede ser un refugio de impotentes, sobre todo políticamente. Yo creo que realmente la clase media, que es la que más lee, lo hace para olvidar, lee para no pensar el país, para evadirse de la realidad, del país, del mundo. La escritura es la forma de salir de la impotencia, el modo de asumir la palabra, de hacerla real 5 .

Debemos, pues, interrogar a la realidad para buscar nuevos sentidos a las prácticas y a los artefactos educativos, para usar aquéllas de forma "comprehensiva" (i. e. abarcadora de distintas realidades y demandas sociales y personales) y éstos de forma heurística, capaces, pues, de revelarnos nuevos sentidos.

A este respecto, Castoriadis habla de dos facetas complementarias del lenguaje: Legein, reunir la información, agrupar, comprender a partir de todo lo que podamos recibir y entender (y eso forma parte de los artefactos que vienen pautados socialmente y traen una historia consigo), y del otro, Teukhein como forma de hacer, actuar, construir. En ambos casos, el docente tiene un papel estratégico: debe orientar en el sentido de cómo conectar todo lo que llega al estudiante, y debe orientar también en las prácticas. De este modo, en el primer caso, debe ayudar particularmente en todo lo que se conoce como tecnología del intelecto, enseñar

5. martín Barbero, op. cit. 
a pensar, a aprender, a crear; en el segundo caso, debe ser como un experto "bricoleur", pues como ni las situaciones ni los contextos de aprendizaje son estándar, debe ser él mismo un modelo de bricolaje al seleccionar sus "artefactos".

Es lo que algunos autores (Brown, Lewis y Harcleroad, 1975) denominaron "producción local de recursos". Esto, en cierto modo, no es nuevo, y ya existe en la literatura pedagógica una tendencia a hablar de materiales autónomos, autoinstructivos, etc., adaptados a diferentes contextos. Lo que suele faltar es la praxis didáctica, la aplicación coherente a la hora de elegir unos recursos o de cómo elaborar materiales que sean adecuados, versátiles y baratos para situaciones específicas de aula, sin que tampoco sean el simple pastiche de materiales preexistentes en el mercado, como viene ocurriendo en algunos casos.

No se trata, pues, de entrar en competencia con el material especializado de las editoriales, sino de implementar recursos que vayan realmente en la línea de un material plural, donde editoriales y material cocreado por profesores-alumnos tengan cada uno su sitio y su sentido. La escuela actual debe ser capaz no sólo de recibir recursos sino de adaptar otros y producir ella misma algunos de sus materiales. También es una alternativa al consumismo, a la marca de fábrica, a la producción en serie, porque lo que hace es optimizar unos recursos existentes y fabricar con ellos otra cosa o dar otra funcionalidad a un objeto preexistente. Hay materiales y equipos didácticos de todas las áreas curriculares, que se compran en el mercado y que son como artefactos cuasiperfectos, cerrados, que dejan poco margen a ser completados de forma diferente a como vienen pautados. Por el contrario, hay recursos disponibles dentro de la comunidad educativa y/o de su entorno de un valor insospechado. El profesor, como el médico, sólo puede prescribir la prácti$\mathrm{ca} /$ artefacto apropiados una vez hecho el diagnóstico, conocido el paciente y su entorno, y en forma provisoria, con un seguimiento.

La sala letrada o el aula eficiente no es la que más aparatos y/o libros tenga sino aquella que permita desarrollar mejores prácticas e integrar artefactos más flexibles, por eso una biblioteca o una sala de ordenadores en silencio donde sólo se oiga el ruido del teclado o del pasar de las páginas no son precisamente modelos de salas letradas. Sí lo son más los cafés-tertulia, las ludotecas, los rincones de lectura, los seminarios y espacios de conversación y de co-creación de contenidos.

Las salas letradas no son sólo esos espacios llenos de estímulos (alfabetos, pared de palabras, etc.) propios de la educación infantil; las salas letradas no deben estar empapeladas de textos sino de prácticas y artefactos orientados a un aprendizaje dialógico, donde lo oral, lo impreso, lo audiovisual y lo digital en fin se superpongan como continentes o muebles de un salón que hay que habitar y apropiarse. La experiencia auténtica, los textos auténticos familiares, privados (las escrituras ordinarias) deben introducirse en este hábitat, por ejemplo, un producto cualquiera, y sobre él aplicar la metodología ABP (o PBL, Project Based Learning) u otra similar. De este modo, una sala de clase, basada en estas metodologías de proyectos o problemas, se convierte en un espacio de lectura de la realidad 
a través de diferentes aproximaciones y herramientas, donde es más fácil de producir ese aprendizaje liberal de que habla Oakeshott (2009), a través precisamente del cruce de discursos y lenguajes.

El haber focalizado la reflexión en algunos puntos no debe hacernos olvidar el sentido amplio o expandido del concepto que nos ocupa, así, cabe hablar igualmente de "instrumentos psicológicos" o "artefactos psicológicos" en la medida en que, por ejemplo, la dinámica de grupos es también categorizable como un instrumento, desde una perspectiva psicopedagógica (Kozulín, 2000).

\section{LA SÍNTESIS NECESARIA: HACIA UN ENFOQUE ARTIFACTUAL DE LA ALFABETIZACIÓN Y SUS IMPLICACIONES EDUCATIVAS}

Según el citado enfoque de los Nuevos Estudios de Literacidad (Cassany, 2006) una buena parte de las prácticas de lectura bien se pueden describir a la luz de los artefactos culturales que se crean. De hecho, la literacidad clásica se definía a partir de las competencias que podían ser útiles para el manejo de los soportes de lectura convencionales -básicamente el libro o material escriturario en todas sus variantes, desde un cuaderno a una enciclopedia, plumas y otros accesorios-, pero la literacidad electrónica involucra otro tipo de dispositivos.

El enfoque artifactual de la alfabetización (Pahl y Rowsell, 2011) propugna la multimodalidad, lo cual implica en el caso de la alfabetización enfrentar a los alumnos no sólo con la lectoescritura convencional sino con las otras culturas, la oralidad, la cultura mediática y la cibercultura, ámbitos donde precisamente hay un universo de artefactos distintos a los de la cultura letrada, por ejemplo la carátula de un vídeo, un hipertexto o una performance acompañada de una serie de objetos (v.gr. kamishibai, tapetes de lectura, etc.). Es decir, se contempla el mundo objetual desde una perspectiva más amplia, incorporando otros canales, soportes, texturas, y propiciando con todo ello una reflexión y asumir un punto de vista crítico. De este modo, se trata de apartarse un poco de las cosificaciones propias del mundo de la cultura letrada clásica, por ejemplo, la lectura y la escritura no se "anclan" sólo en el formato libro, sino dentro de todas las prácticas y soportes de la comunidad.

Es un enfoque coherente con las recomendaciones de la UNESCO sobre la alfabetización situada, esto es, sobre usar los entornos de proximidad como focos de la alfabetización, y eso debe incluir a los objetos propios de ese contexto cultural. Pero, yendo un poco más allá, esa aproximación busca conectar los objetos con la vida de los individuos y las comunidades, por ejemplo, las fotografías, máquinas de coser u otros enseres domésticos que cuenten historias de migración, o cualquier otra historia significativa, que evoquen narrativas de personas, de grupos, de empresas..., es decir, todo lo que sea socialmente significativo en ese medio, y que no puede pasar por alto como parte de su tradición alfabetizadora. Podemos poner ejemplos relativamente simples: es cierto que el canon escolar es más o 
menos homogéneo, pero también es verdad que cuando se eligen unos textos por parte de una comunidad escolar, a menudo son revestidos de objetos que son precisamente los significativos de ese ambiente. Pensemos en una dramatización o en un museo del cuento a propósito de un cuento clásico: las comunidades los materializan con técnicas de bricolaje, y en esa adaptación surgen esos objetos enraizados en el medio. De hecho, Pahl y Rowsell recomiendan la narración de cuentos como formas de crear espacios de aprendizaje "ad hoc".

En conclusión, deberíamos dar por sentado que lo sustancial no son las tecnologías ni los dispositivos más novedosos en sí sino el tipo de prácticas culturales que se generan, porque esas prácticas sí que son determinantes a la hora de tipificar la cultura. Incluso, en el enfoque artifactual que acabamos de describir, la cultura material que debe primarse no es la estándar sino la que esté más cercana y más enraizada con el alumno y su entorno. Y eso tiene que ver no sólo con los artefactos materiales sino también con los mentales, por eso, recomiendan partir de los relatos y objetos biográficos como el caso que citamos de las fotografías, es decir, todo lo que esté más ligado a la vida cotidiana, en un enfoque global que se acerca mucho a la perspectiva etnográfica. Precisamente, uno de los lemas de ésta es "hacer visible lo invisible" y es cierto que hay muchas prácticas y objetos que pasan desapercibid os y que sin embargo son nucleares para la alfabetización, por ejemplo, los post-it como ejemplos de objetos y escrituras fragmentarias que se asocian a los recados de la compra, las notas dejadas sobre una página en revisión, etc.

Reivindicar el mundo de los objetos, de la materialidad como fuente de la alfabetización es una manera de "construir comunidad" y un marco crítico de indagación y reflexión, más allá de las preconcepciones, pues de lo que se trata es de ayudar a transformar en positivo la comunidad a través de artefactos materiales y mentales, por ejemplo, creando "artefactos digitales" con la historia de la comunidad.

Aunque Pahl y Rowsell aducen diversos ejemplos propios del mundo anglosajón, podríamos poner un ejemplo concluyente desde el punto de vista de nuestro patrimonio cultural. Acercarse al mundo de los textos de Pablo Neruda no sería sólo, según este enfoque, leer sus poemas en una edición estandarizada. Deberíamos poder recorrer con él sus propios objetos, que tanto hablan de su singladura vital, de Chile, de América y, finalmente, de su relación misma con Europa y España: Neruda fue un coleccionista de objetos tan singulares como mascarones de proa, barquitos armados dentro de botellas, brújulas, libros sobre pájaros y plantas, narraciones de viajes y todo un sinfín de artefactos maravillosos que se convierten ipso facto en objetos y fuentes de alfabetización para quien se acerque a conocer su mundo, tanto o más que cualquier estudio erudito sobre sus temas poéticos. 


\section{REFERENCIAS BIBLIOGRÁFICAS}

BajTín, M. (1974) La cultura popular en la Edad Media y el Renacimiento. El contexto de François Rabelais. Barcelona, Barral Editores.

Barré-De MiniaC Brissaud, C. y Rispail, M. (eds.) (2004) La Littéracie. Conceptions théoriques et pratiques d'enseignement de la lecture-écriture. Paris, L'Harmattan, 31.

Barton, D. y Hamilton, M. (1998) Local Literacies. Reading and Writting in one Community. London, Routledge.

BAudrillard, J. (1993) Cultura y simulacro. Barcelona, Ed. Kairós.

Benjamin, W. (1973) El narrador. Revista de Occidente, 43, 301-333, tr. Jesús Aguirre. Madrid.

Bourdieu, P. (1992) Les Règles de l'art: Genèse et structure du champ littéraire (Libre Examen). Paris, Seuil.

BRINGUÉ, X. y SÁDABA, Ch. (coords.) (2008) La Generación Interactiva en Iberoamérica: niños y adolescentes ante las Pantallas. Barcelona, Editorial Ariel.

Brown, L. y Harcleroad, F. F. (1975) Instrucción Audiovisual. México, Trillas.

CAlABRESe, O. (1994) La Era Neobarroca. Madrid, Cátedra.

Calvino, I. (1992) Por qué leer los clásicos. Barcelona, Tusquets.

Cassany, D. (2006) Tras las líneas. Barcelona, Anagrama.

Castillo Gómez, A. (2005) Historia minima del libro y la lectura. Madrid, Siete Mares.

CASTORIadis, C. (1999) L'institution imaginaire de la société. Paris, Éditions du Seuil.

CHARTIER, R. (1994) El orden de los libros: lectores, autores, bibliotecas en Europa entre los siglos XIV y XVIII. Barcelona, Gedisa.

Damasio, A. (2006) El error de Descartes: la emoción, la razón y el cerebro bumano. Barcelona, Editorial Crítica.

De Zubiría, M. (1997) Aplicaciones de los mentefactos al aula de clase. Postgrado en Desarrollo Intelectual y Educación. Colombia, Desarrollo Intelectual y Educación.

Dennet, D. (1995) La conciencia explicada. Paidós, Barcelona.

EFRÓN, G. (2008) Jóvenes: entre las culturas cibernéticas y la cultura letrada. Curso de posgrado virtual Educación, imágenes y medios. Buenos Aires, FLAcso.

FreIRE, P. (1970) Pedagogía del oprimido. Madrid, Siglo XXI Editores.

FREIRE, P. (1998) La importancia de leer y el proceso de liberación. Madrid, Siglo XXI.

GALINDO, J. (2006) Cibercultura: un mundo emergente y una nueva mirada. México, Conaculta e Instituto Mexiquense de Cultura.

GEE, J. P. (2004) Lo que nos enseñan los videojuegos sobre el aprendizaje y el alfabetismo (J. M. Pomares, trad.). Málaga, Ediciones Aljibe (trabajo original publicado en 2003).

Goody, J. (1996) Cultura escrita en sociedades tradicionales. Barcelona, Gedisa.

HAVELOCK, H. (1996) La musa aprende a escribir. Reflexiones sobre oralidad y escritura desde la Antigüedad hasta el presente. Barcelona, Paidós.

Holland, D. y Cole, M. (1995) Between discourse and schema: reformulating a culturalhistorical approach to culture and mind. Anthropology and Education Quarterly, 26 (4), 475-490. http://dx.doi.org/10.1525/aeq.1995.26.4.05x1065y.

HuxLEY, J. S. (1955) Editorial Invitado: evolución, cultural y biológica. Anuario de Antropologia, 2-25. 
IsNaRD, E. (2009) Jack Goody, Pouvoirs et savoirs de l'écrit. L'Homme, 274-277. Consultado el 1 de mayo de 2011.

http://lhomme.revues.org/index21208.html.

Jameson, F. (1991) Ensayos sobre el posmodernismo. Buenos Aires, Imago Mundi, 102.

Jancovich, M. (2002) Horror: The film reader. Londres, Routledge, 77-90.

JENKINS, H. (2008) Convergence culture: la cultura de la convergencia de los medios de comunicación. Barcelona, Paidós.

Kozulin, A. (2000) Instrumentos psicológicos: la educación desde una perspectiva sociocultural. Barcelona, Paidós.

LINK, D. (1997) Literaturas comparadas, estudios culturales y análisis textual: por una pedagogía. Filología, n. ำ 1-2, 5-14.

Lotman, Y. (1979) Semiótica de la cultura. Madrid, Cátedra.

MARTín BARBERO, J. (2005) Los modos de leer. En la Semana de Lectura CERlalC Omar Rincón (comp.). Centro de Competencia en Comunicación para América Latina.

Martos García, A. (2008) El poder de la con-fabulación Narración colectiva, fan fiction y cultura popular. Espéculo, 2008, n.․․ 4, versión digital. http://www.ucm.es /info/especulo/m_amo/amo_4.html.

Moles, A. (1978) Sociodinámica de la Cultura. Barcelona, Paidós.

OAkeshotт, M. (2009) La voz del aprendizaje liberal. Buenos Aires/Madrid, Katz editores S. A.

Olson, D. (1994) El mundo sobre el papel. Cap. XI. La representación de la mente. Los orígenes de la subjetividad y Cap. XII. La Constitución de la mente letrada. Barcelona, Editorial Gedisa.

ONG, W. (1987) Oralidad y escritura, tecnologías de la palabra. México, Fondo de Cultura Económica.

PAHL, K. H. y Rowsell, J. (2011) Artifactual Critical Literacy: A New Perspective for Literacy Education. Berkeley Review of Education, 2 (2), Brock University.

Piscitelli, A. (1995) Las ciberculturas. En la era de las máquinas inteligentes. Buenos Aires, Paidós.

Prensky, M. (2005) In Educational Games, Complexity Matters, Mini-games are Trivial - but "Complex" Games Are Not - An important Way for Teachers, Parents and Others to Look At Educational Computer and Video Games. Educational Technology, vol. 45, n. .4 , julio-agosto.

QuaIn, B. (2002) El poderío de ser prosumidor. Bogotá, Internet Services Corporatio.

SIRI, L. (2000). Un análisis de YouTube como artefacto sociotécnico. Revista académica de la Federación Latinoamericana de Facultades de Comunicación Social. Consultado el 12 de marzo de 2009. http://www.dialogosfelafacs.net/77/artículos/pdf/77LauraSiri.pdf.

Vygotsky, L. (1994) The problem of the environment, en VAn DeR VeER, R. y VALsiner, J. (eds.) The Vygotsky reader. Cambridge, Massachusets, Blackwell Publishers. 